\title{
Diffusion Bonding of Surface Self-nanocrystallized Ti-4AI-2V and OCr18Ni9Ti by Means of High Energy Shot Peening
}

\author{
J. HAN, G. M. SHENG and X. L. ZHOU \\ College of Materials Science \& Engineering, Chongqing University, Chongqing, 400030, P. R. China. \\ E-mail: gmsheng@cqu.edu.cn
}

(Received on April 8, 2008; accepted on May 26, 2008)

\begin{abstract}
By means of high energy shot peening (HESP), surface nanostructured layers were synthesized on the ends of Ti-4Al-2V titanium alloy and 0Cr18Ni9Ti austenitic stainless steel bars. Using the peened surfaces for mating surface, constant temperature and pressure diffusion bonding (CTPDB) was applied to prepare joints of $\mathrm{Ti}-4 \mathrm{Al}-2 \mathrm{~V} / 0 \mathrm{Cr} 18 \mathrm{Ni9Ti}$ in the temperature rang of $800-900^{\circ} \mathrm{C}$ for $20 \mathrm{~min}$ under a uniaxial load of $8 \mathrm{MPa}$ in vacuum. Tensile strengths of joints were tested, longitudinal section microstructures of joints were analyzed by using scanning electron microscope (SEM), meanwhile, concentrations of $\mathrm{Fe}, \mathrm{Ti}, \mathrm{Cr}$ and $\mathrm{Ni}$ in diffusion layers were measured by using energy dispersive spectroscope (EDS), and the diffusion coefficient and diffusion activation energy of Fe atom in the Ti-4Al-2V side were calculated. Results shows that the maximum tensile strength of $327 \mathrm{MPa}$ is obtained when bonding temperature is $850^{\circ} \mathrm{C}$, the diffusion activation energy of Fe atom is far less than that in coarse grain sample, and the diffusion coefficient of Fe atom is higher than that in convention coarse grain sample.
\end{abstract}

KEY WORDS: high energy shot peening (HESP); constant temperature and pressure diffusion bonding (CTPDB); diffusion coefficient; diffusion activation energy.

\section{Introduction}

Displaying low density, high specific strength, rich corrosion resistance, the good high temperature strength and low temperature ductility, titanium and titanium alloy were applied widely to multiple fields such as the aerospace, petrochemical industry and nuclear power. But, due to the low Young's modulus and poor high temperature creep, ${ }^{1,2)}$ titanium alloy is commonly jointed with stainless steel by means of diffusion bonding to fabricate workpiece used in hot temperature environment. However, the tremendous physicochemical performance differences between titanium alloy and stainless steel results in formation of brittle intermetallic compounds, in the vicinity of interface, growth of grains, and the increment of joint deformation while bonding time is superlong and bonding temperature is overhigh, which deteriorate badly the performance of joints.

It is well known that nanocrystalline (nc) materials exhibits many novel properties relative to their coarse-grained counterparts, such as high strength and hardness, good superplasticity at low temperature and excellent wear property, ${ }^{3)}$ furthermore, a large number of defective grain boundaries (GBs) in nanostructured materials may act as fast atomic diffusion channels, hence greatly enhancing atomic diffusivities. ${ }^{3,4)}$ Since the Germany scientist $\mathrm{H}$. Gleiter $\left.^{4}\right)$ firstly produced nc sample by means of metal gas condensation and in situ consolidation in the early 1980s, various preparation methods have been developed to synthesis bulk nc materials. K. Lu et al. ${ }^{5)}$ have developed a new approach, surface self-nanocrystallinzation (SSNC), to prepare bulk nc materials. The nc materials from the technology include a large volume fraction of stored energy and non-equilibrium defective resulting in refining of coarse grains such as dislocations, vacancy, subboundary, which may promote chemical reaction of different atoms and enhance atomic diffusion coefficient. ${ }^{6,7)}$ The SSNC has been applied to chemical heat treatment of many metal materials, research results ${ }^{8-13)}$ showed that atomic diffusion coefficient were greatly enhanced in the nanostructured surface layer, so as to can decrease heat treatment temperature and shorten heat treatment time greatly, which will inaugurate new path for low-temperature and high-efficiency chemical heat treatment of metal materials.

However, so far, applying the SSNC to diffusion bonding of metal materials has not been read in all literatures. In present work, the SSNC was applied to diffusion bonding of Ti-4Al-2V titanium alloy and 0Cr18Ni9Ti stainless steel bars, aiming at increasing atomic diffusion coefficient in the course of diffusion bonding, reducing bonding temperature, shorting bonding time, and improving mechanical property of joints. And the strength of joints and Fe atomic diffusion kinetics in diffusion layer were researched.

\section{Experimental}

\subsection{Experimental Materials}

Commercial Ti-4Al-2V titanium alloy and 0Cr18Ni9Ti stainless steel bars $(\Phi 12 \mathrm{~mm} \times 30 \mathrm{~mm}$ in size $)$, with compo- 
Table 1. Chemical composition of tested materials (wt $\%)$.

\begin{tabular}{cccccccccccccccc}
\hline Alloy & $\mathrm{Fe}$ & $\mathrm{Ti}$ & $\mathrm{C}$ & $\mathrm{Si}$ & $\mathrm{Ni}$ & $\mathrm{Cr}$ & $\mathrm{S}$ & $\mathrm{Mn}$ & $\mathrm{P}$ & $\mathrm{Al}$ & $\mathrm{V}$ & $\mathrm{N}$ & $\mathrm{H}$ & $\mathrm{O}$ \\
\hline 0Cr18Ni9Ti & rest & 0.29 & 0.04 & 0.47 & 8.37 & 17.22 & 0.02 & 1.21 & 0.034 & - & - & - & - & - \\
Ti-4Al-2V & 0.069 & rest & 0.01 & 0.04 & - & - & - & - & - & 4.5 & 2.2 & 0.023 & 0.003 & 0.05 \\
\hline
\end{tabular}
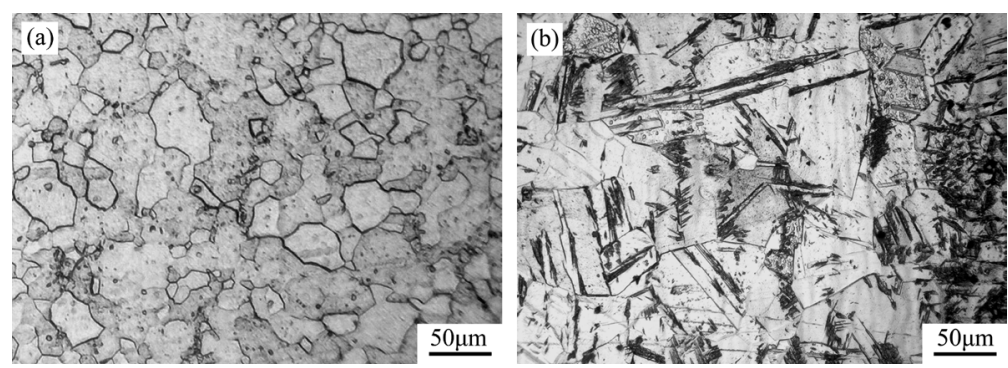

Fig. 1. Optical photographs of samples. (a) Ti-4Al-2V titanium alloy; (b) 0Cr18Ni9Ti stainless steel.

sition as shown in Table 1, were selected for experiment. To eliminate the effect of rolling deformation and obtain homogeneous coarse equiaxial grains, the $\mathrm{Ti}-4 \mathrm{Al}-2 \mathrm{~V}$ bars were annealed for $3 \mathrm{~h}$ at $750^{\circ} \mathrm{C}$ in vacuum furnace, and the $0 \mathrm{Cr} 18 \mathrm{Ni}$ Ti stainless steel bars were hold $1 \mathrm{~h}$ for solution treatment at $1100^{\circ} \mathrm{C}$ in vacuum furnace. After heat treatment, the $\mathrm{Ti}-4 \mathrm{Al}-2 \mathrm{~V}$ microstructure constitutes mainly coarse equiaxial $\alpha$ grains (20-50 $\mu \mathrm{m})$ and a small amount $\beta$ phase (as shown in Fig. 1(a)), the stainless steel microstructure chiefly consist of austenite with twins and a small volume fraction martensite(as shown in Fig. 1(b)).

\subsection{Surface Self-nanocrystallization Treatment}

Before diffusion bonding, the ends of Ti-4Al-2V titanium alloy and $0 \mathrm{Cr} 18 \mathrm{Ni}$ Ti stainless steel bars were treated to obtain surface nanostructured layer by means of HESP. Figure 2(a) shows a schematic illustration of the HESP treatment set-up used in the present work. Steel balls of $1 \mathrm{~mm}$ in diameter were thrown with high velocity to the end face of the bar samples under peening pressure of about $0.6 \mathrm{MPa}$. Each peening of the ball will result in severe plastic deformation on the surface of the treated sample (as shown in Fig. 2(b), ${ }^{8)}$ repeated impacting on the sample surface over short period of time (in this work, treatment time is $5 \mathrm{~min}$ ) leads to a progressive refinement of coarse grains into nanometer regime. Prior to the treatment, the treated ends were polished manually with silicon carbide papers to $1200^{\#}$ and then mechanically polished with $\mathrm{Al}_{2} \mathrm{O}_{3}$ polishing powder to achieve finish surface. It was note that a restrain sleeve part with $2_{-0}^{+0.5} \mathrm{~mm}$ inner diameter was machined to grip the treatment end of sample and impede metal to flow away rim of the surface (as shown in Fig. 2(a)).

Longitudinal-sectional observations of the treated samples were preformed on a TESCAN VEGA II scanning electron microscope (SEM, operating at a voltage of $30 \mathrm{kV}$ ). Microstructure features in the surface layer were characterized by using a Philip Tecnai-20 transmission electron microscope (TEM, operating at a voltage of $200 \mathrm{kV}$ ). Plane-view and cross-sectional thin foils for TEM observations were prepared by means of cutting, grinding, dimpling and a final ion thinning at low temperatures. The quantitative X-ray diffraction (XRD) analysis of the surface

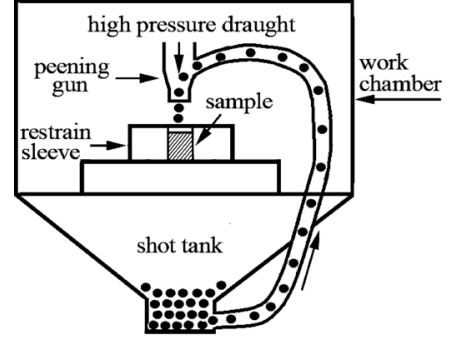

(a)

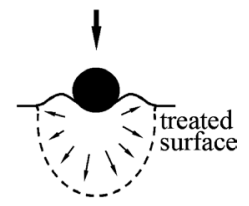

(b)
Fig. 2. (a) The illustration of the HESP treatment set-up and (b) the local plastic deformation in surface layer by the peening of the shot.

layer in the HESP treated samples were carried out on a D/max-2400 X-ray diffractometer $(12 \mathrm{~kW})$, with $\mathrm{Cu} K_{\alpha}$ radiation (wavelength $\lambda_{\alpha 1}=0.154056 \mathrm{~nm}, \lambda_{\alpha 2}=0.154439 \mathrm{~nm}$ was eliminated by a graphite monochromator using its (0002) reflection), slit parameters of the diffractometer are $1^{\circ}-1^{\circ}-0.30 \mathrm{~mm}$. The average grain size and mean microstrain on the top surface were calculated from line broadening of Bragg diffraction peaks.

\subsection{Diffusion Bonding Experiment}

After the HESP treatment, the roughness of the treated surface was increased in some short. In order to satisfying with interface condition of diffusion bonding, treated surface used for mating surface of diffusion bonding were prepared by conventional metallographic technology, cleaned in acetone and dried in air. Constant temperature and pressure diffusion bonding (CTPDB) of Ti-4Al-2V titanium alloy and $0 \mathrm{Cr} 18 \mathrm{Ni} 9 \mathrm{Ti}$ stainless steel bars was carried out in the Gleeble 1500-D vacuum chamber, under $8 \mathrm{MPa}$ uniaxial load for $20 \mathrm{~min}$, the diffusion bonding process drawing is shown in Fig. 3, the bonding temperature are 800, 825, 850, 875 and $900^{\circ} \mathrm{C}$ respectively, both heating rate and cooling velocity are set as $5^{\circ} \mathrm{C} / \mathrm{s}$. Two joints were prepared at each bonding temperature, one was experimented for tensilestrength, and other one was used for observed microstructure of longitudinal section.

After diffusion bonding, joints were annealed for $1 \mathrm{~h}$ at $400^{\circ} \mathrm{C}$ in vacuum furnace to eliminate bonding stress. 
Tensile samples were machined to $\Phi 10 \mathrm{~mm} \times 50 \mathrm{~mm}$ in size, and experimented on the Instron-1342 style instron. Longitudinal sections were taken from joints and prepared by usual grinding and polishing techniques. The titanium alloy and stainless steel sides were etched with Kroll reagent $\left(6 \mathrm{~mL} \mathrm{HCl}, 2 \mathrm{~mL} \mathrm{FH}\right.$ and $\left.92 \mathrm{~mL} \mathrm{H}_{2} \mathrm{O}\right)$ and aqua regia $\left(60 \mathrm{~mL} \mathrm{HCl}, 20 \mathrm{~mL} \mathrm{HNO}_{3}\right.$ and $\left.20 \mathrm{~mL} \mathrm{H}_{2} \mathrm{O}\right)$, respectively. Microstructures in the reaction zone were observed by a TESCAN VEGA II scanning electron microscope (SEM, operating at a voltage of $30 \mathrm{kV}$ ), meanwhile, distributions of $\mathrm{Fe}, \mathrm{Ti}, \mathrm{Cr}$ and $\mathrm{Ni}$ in diffusion layers on the titanium alloy side were monitored by using a fully quantitative X-ray energy dispersive spectroscope (EDS).

\section{Results}

\subsection{Microstructure of Surface Self-nanocrystallization Treatment}

After HESP treatment of samples, the longitudinal-sectional SEM morphology of titanium alloy shows a plastic deformation layer of about $253.52 \mu \mathrm{m}$ was generated below top surface (as shown in Fig. 4(a)), the plastic deformation was gradually exacerbated with decreasing of depth to the top surface, while the depth was reduced to about $121.81 \mu \mathrm{m}$, severe plastic deformation was created due to

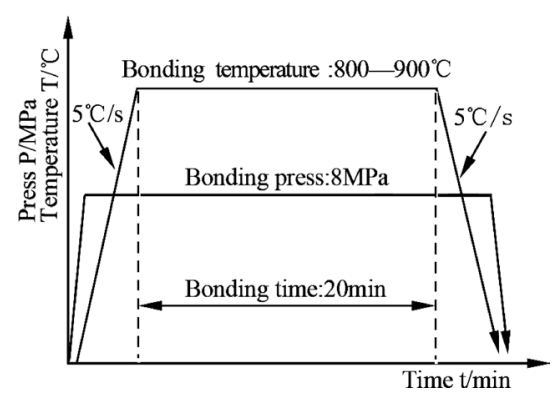

Fig. 3. Technology curve of constant temperature and pressure diffusion bonding. greater stress and strain. Cross-sectional TEM morphology about $20 \mu \mathrm{m}$ depth to the top surface in titanium alloy indicates nanograins with about $50 \mathrm{~nm}$ were formed (as shown in Fig. 4(b)), the corresponding selected area electron diffraction (SAED) pattern shows these nanograins have nearly random crystallographic orientation. Within $50 \mu \mathrm{m}$ below the top surface in the titanium alloy samples, nanograins with below $100 \mathrm{~nm}$ were produced after $5 \mathrm{~min}$ HESP.

In the $0 \mathrm{Cr} 18 \mathrm{Ni}$ Ti stainless steel samples, the plastic deformation layer thickness was about $615.84 \mu \mathrm{m}$, and the severe plastic deformation layer was about $184.56 \mu \mathrm{m}$, as shown in Fig. 4(c). Cross-sectional TEM morphology about $30 \mu \mathrm{m}$ depth shows that equiaxial nanograins with about $60 \mathrm{~nm}$ were formed in the $0 \mathrm{Cr} 18 \mathrm{Ni}$ Ti stainless steel sample, the corresponding SAED pattern reveals nanograins have random crystallographic orientation (as shown in Fig. 4(d)). By TEM observation, nanograins layer about $80 \mu \mathrm{m}$ thickness was generated in the 0Cr18Ni9Ti after HESP.

On the top surface of treated samples, Full Wave at Half Maximum (FWHM) of diffraction peaks were measured by the MDI Jade5.0 (a X-ray analysis software). The average grain size and mean microstrain on the top surface were calculated from broadening of diffraction peaks, by using formula as follows:

$$
\frac{F W(S) \cdot \cos (\theta)}{\lambda}=\frac{K}{D}+4 \cdot \varepsilon \cdot \frac{\sin \theta}{\lambda}
$$

Where $F W(S)^{D}=F W H M^{D}-F W(I)^{D}$ is FWHM of peaks after detracting broadening led by the diffractometer itself; $K$ is a constant, $K=0.89$ here; $\lambda$ is the wave length of the $\mathrm{Cu} k_{\alpha 1}$ irradiation; $\theta$ is Bragg diffraction angle; $D$ is mean grain size; $\varepsilon$ is mean lattice strain. By performing a least square fit $(F W(S) \cdot \cos (\theta) / \lambda$ plotted against $(\sin \theta) / \lambda$ for all of the measured peaks of a sample, one is able to determine the mean grain size $D$ and the mean lattice strain $\varepsilon$ (as shown in Table 2).
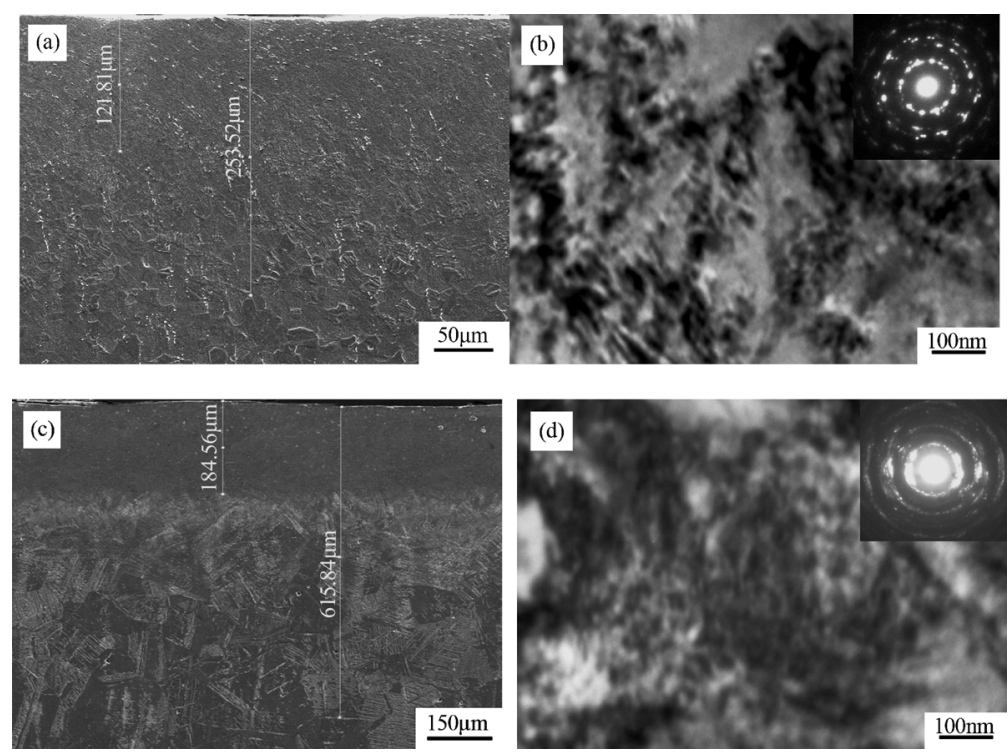

Fig. 4. SEM and TEM of treated samples by means of HESP. (a) Longitudinal section SEM of treated Ti-4Al-2V; (b) TEM of treated $\mathrm{Ti}-4 \mathrm{Al}-2 \mathrm{~V}$ at the $20 \mu \mathrm{m}$ depth from top surface; (c) longitudinal section SEM of treated $0 \mathrm{Cr} 18 \mathrm{Ni} 9 \mathrm{Ti}$; (d) TEM of treated Ti-4Al-2V at the $30 \mu \mathrm{m}$ depth from top surface. 
Table 2. Average grain size and lattice distortion of treated samples.

\begin{tabular}{ccc}
\hline Alloy & Average grain size (nm) & Average lattice distortion (\%) \\
\hline $\mathrm{Ti}-4 \mathrm{Al}-2 \mathrm{~V}$ & 33.3 & 0.087 \\
$0 \mathrm{Cr} 18 \mathrm{Ni9Ti}$ & 50.0 & 0.170 \\
\hline
\end{tabular}

Table 3. Tensile strength and compressibility of bonded joints.

\begin{tabular}{ccc}
\hline Bonding temperature $\left(\mathrm{T} /{ }^{\circ} \mathrm{C}\right)$ & Tensile strength $\left(\sigma_{\mathrm{b}} / \mathrm{MPa}\right)$ & Compressibility $(\varepsilon / \%)$ \\
\hline 800 & Fracture when machining & 0.03 \\
825 & 250 & 1.13 \\
850 & 327 & 4.43 \\
875 & 275 & 7.12 \\
900 & 229 & 15.5 \\
\hline
\end{tabular}

\subsection{Tensile Strength of Joints}

Tensile strength of joints at different bonding temperature are summarized in Table 3, thereinto, the strength of joint at $800^{\circ} \mathrm{C}$ has not been obtained due to fracture of joint while machining. From the Table 3, one can knows the maximum strength of $327 \mathrm{MPa}$ with $4.43 \%$ compressibility was achieved while bonding temperature being $850^{\circ} \mathrm{C}$, subsequently, the bond strength decrease with increasing of bonding temperature, at $900^{\circ} \mathrm{C}$, the minimum strength of $229 \mathrm{MPa}$ was achieved. In the course of diffusion bonding, compressibility of joints is increasing with rising of bonding temperature.

CTPDB of titanium alloy and stainless steel have been already researched quite a bit, but bond strength of joint has not been enhanced effectively, improving joint strength is still effort of material researcher. So far, in the all literatures about CTPDB of titanium alloy and stainless steel, the maximum tensile strength of $306 \mathrm{MPa}$, which $\mathrm{CP} \mathrm{Ti}$ and MDSS(commercial pure $\mathrm{Ti}$ and micro-duplex stainless steel) was bonded for $90 \mathrm{~min}$ at $850^{\circ} \mathrm{C}$ and $3 \mathrm{MPa}$ presure, was obtained by S. Kundu et al., ${ }^{14)}$ obviously, the bonding time is superlong and efficiency is lower in the process. CTPDB was applied to produce joints of TA1 alloy and $1 \mathrm{Cr} 18 \mathrm{Ni}$ Ti stainless steel by Yingcai Zhang, ${ }^{15)}$ and the joint strength reached only $31.5-207.5 \mathrm{MPa}$ at 800 $1100^{\circ} \mathrm{C}, 50-100 \mathrm{MPa}$, for $30-180 \mathrm{~min}$, in the bonding process, bond time is longer, upper limit of bond temperature is higher, and the joint strength have not been enhanced effectively. In our prior period researches, CTPDB was applied to produce joints of Ti-4Al-2V alloy and $0 \mathrm{Cr} 18 \mathrm{Ni} 9 \mathrm{Ti}$ stainless steel with coarse grains, the maximum strength of $264 \mathrm{MPa}$ was achieved at $850^{\circ} \mathrm{C}, 8 \mathrm{MPa}$ for $30 \mathrm{~min} .{ }^{16)}$ In present work, tight junctions of $\mathrm{Ti}-4 \mathrm{Al}-2 \mathrm{~V}$ and $0 \mathrm{Cr} 18 \mathrm{Ni} 9 \mathrm{Ti}$ bars with nanostructured interface were obtained by means of CTPDB, the maximum strength of $327 \mathrm{MPa}$ was achieved within no more than $20 \mathrm{~min}$, which shows surface self-nanocrystallization treatment for bond interface redounds to improvement of the bond strength.

\subsection{SEM and EDS of Joints}

The SEM image of the transition joints are given in Fig.

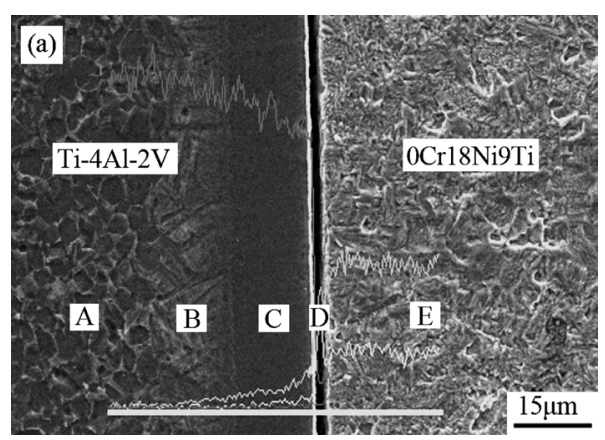

Fig. 5. SEM and concentration profiles of major elements across interface.

5. On the longitudinal sections, A, B, C, D and E regions were divided in the light of microstructures feature. Region A is titanium alloy matrix consisted of fine grains (less than $10 \mu \mathrm{m}$ in size), region $\mathrm{B}$ is acicular $\alpha-\beta$ Ti occurring from the decomposition of $\beta$-Ti during cooling, region $\mathrm{C}$ is $\beta$-Ti solid solution, region $\mathrm{D}$ is intermetallic compound which presents black groove after etched, and region $\mathrm{E}$ is stainless steel base. ${ }^{17)}$ Longitudinal sections of all joints also are consisted of five regions mentioned above, just that each region magnitude vary with increasing of bonding temperature (as shown in Fig. 8). Corresponding line scanning energy spectrum (in the Fig. 5) shows $\mathrm{Fe}, \mathrm{Cr}$ and $\mathrm{Ni}$ atoms have diffused into titanium alloy with different distances, and Ti atoms diffused into stainless steel also. Diffusion distances of $\mathrm{Fe}$ and $\mathrm{Ti}$ atoms were measured respectively, and summarized in Table 4, they both do not include thickness of intermetallic compound, i.e. the thickness of region D. The Table 4 shows the diffusion distances of $\mathrm{Fe}$ and $\mathrm{Ti}$ atoms increase with increasing of bonding temperature, the minimum diffusion distances of $\mathrm{Fe}$ and $\mathrm{Ti}$ are $17.8 \mu \mathrm{m}$ and $3 \mu \mathrm{m}$ respectively when bonding temperature is $800^{\circ} \mathrm{C}$. Comparing with in coarse grain sample, diffusion distances of $\mathrm{Fe}$ and $\mathrm{Ti}$ in the sample with nanostructured microstructures are increased aggressively. Literature ${ }^{18)}$ shows the diffusion distance of $\mathrm{Fe}$ atom in coarse grain titanium alloy sample is only about $10 \mu \mathrm{m}$ when Ti- $4 \mathrm{Al}-2 \mathrm{~V}$ and $0 \mathrm{Cr} 18 \mathrm{Ni} 9 \mathrm{Ti}$ was bonded for $30 \mathrm{~min}$ at $875^{\circ} \mathrm{C}$ and $8 \mathrm{MPa}$, at 
Table 4. The diffusion distances of $\mathrm{Fe}$ and $\mathrm{Ti}$ atoms at different temperatures.

\begin{tabular}{cccccc}
\hline Bonding temperature $\left(\mathrm{T}^{\circ} \mathrm{C}\right)$ & 800 & 825 & 850 & 875 & 900 \\
\hline Fe diffusion distance $(\mathrm{d} / \mu \mathrm{m})$ & 17.8 & 24.4 & 32.0 & 32.5 & 32.4 \\
Ti diffusion distance $(\mathrm{d} / \mu \mathrm{m})$ & 3.0 & 4.0 & 6.1 & 9.2 & 10.2 \\
\hline
\end{tabular}

Table 5. Measured concentration of Fe by EDS in diffusion zone.

\begin{tabular}{|c|c|c|c|c|c|c|c|c|}
\hline Temperature & \multicolumn{8}{|c|}{ Distance to interface $(x / \mu \mathrm{m})$ and concentration of $\mathrm{Fe}(\mathrm{C} / \mathrm{at} . \%)$} \\
\hline \multirow{2}{*}{800} & $x$ & 5.30 & 10.50 & 15.80 & 21.0 & 26.30 & 31.6 & 36.8 \\
\hline & $\mathrm{C}$ & 7.89 & 5.74 & 2.56 & 1.37 & 1.13 & 0.64 & 0.27 \\
\hline \multirow{2}{*}{825} & $x$ & 4.42 & 8.84 & 13.26 & 17.68 & 22.10 & 26.52 & 30.94 \\
\hline & $\mathrm{C}$ & 10.18 & 6.77 & 5.38 & 4.70 & 3.14 & 3.49 & 1.32 \\
\hline \multirow{2}{*}{850} & $x$ & 2.50 & 7.80 & 13.10 & 18.40 & 23.70 & 29.00 & 34.30 \\
\hline & $\mathrm{C}$ & 14.20 & 9.30 & 7.01 & 4.73 & 3.94 & 2.92 & 1.28 \\
\hline \multirow{2}{*}{875} & $x$ & 3.00 & 8.31 & 13.42 & 18.73 & 24.04 & 29.35 & 34.66 \\
\hline & $\mathrm{C}$ & $14 . .21$ & 8.51 & 7.46 & 5.03 & 2.94 & 2.03 & 1.38 \\
\hline \multirow{2}{*}{900} & $x$ & 2.00 & 9.30 & 16.60 & 23.90 & 31.20 & 38.50 & 45.80 \\
\hline & $\mathrm{C}$ & 14.30 & 9.03 & 6.87 & 4.74 & 3.67 & 2.22 & 1.81 \\
\hline
\end{tabular}
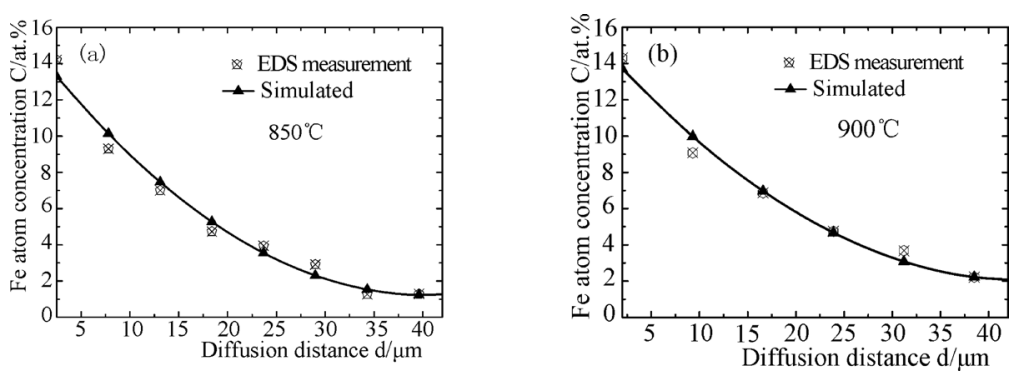

Fig. 6. Profiles of Fe atom concentration versus diffusion distance on titanium alloy sides. (a) Profiles of Fe atom concentration versus diffusion distance at $850^{\circ} \mathrm{C}$; (b) profiles of Fe atom concentration versus diffusion distance at $900^{\circ} \mathrm{C}$.

the same time, Ti atom diffused hardly into in coarse grain stainless steel base, and only formed intermetallic compound on the bonding interface.

In diffusion layer on the titanium alloy sides, concentrations of Fe atom were measured by EDS and summarized in Table 5.

\subsection{Diffusion Kinetics of Fe Atom}

The diffusion coefficients of Fe atom in titanium alloy sides at different bonding temperatures can be gained according to Fick's law. New phase should not be formed in diffusion layer in the light of the Fick's law. However, multiple intermetallic compounds generated in the interface of joints. But, when the concentration of Fe atom is no more than its solid solubility in Ti-4Al-2V, the Fick's law can be still applied to calculate the diffusion coefficient of $\mathrm{Fe}$ atom in $\mathrm{Ti}-4 \mathrm{Al}-2 \mathrm{~V}$ alloy. The maximum solid solubility of $\mathrm{Fe}$ atom in $\beta$ - $\mathrm{Ti}$ at $595^{\circ} \mathrm{C}$ is $15 \mathrm{at} \%$ according to $\mathrm{Fe}-\mathrm{Ti}$ binary phase diagram, ${ }^{19)}$ therefore, while calculating the diffusion coefficient of $\mathrm{Fe}$ atom in titanium alloy, its concentration in $\beta$-Ti should be no more than $15 \mathrm{at} \%$. In addition, in the present work, the diffusion of $\mathrm{Fe}$ atom in $\beta$-Ti is equal to the diffusion in semi-infinite rod, the initial concentration of Fe atom in stainless steel base was supposed $C_{0}$, therefore, the concentration of $\mathrm{Fe}$ atom on the diffusion interface should be $C_{0} / 2$, and $C_{0}$ should be no more than $30 \mathrm{at} \%$.

When diffusion coefficient in different concentrations is constant, the Fick's law may be expressed by Eq. (2):

$$
\frac{\partial C}{\partial t}=D \frac{\partial^{2} C}{\partial x^{2}}
$$

Where $D$ is diffusion coefficient of Fe atom, $C$ is concentration of $\mathrm{Fe}$ at $x$ point, and $t$ is diffusion bonding time. According to the Eq. (2), if the diffusion coefficient $D$ maintains a constant at different concentration, the concentration $C$ should be quadratic function of diffusion distance.

According to datum in the Table 5, scatters of Fe atom concentration versus distance $(x)$ to diffusion interface in titanium alloy sides were drawn (as shown in Fig. 6). Following quadratic function, scatters were simulated into quadratic curves by Matlab software. Results shows the simulated profiles are great agreement with the measured datum, as shown in Fig. 6, which demonstrate the diffusion coefficient of $\mathrm{Fe}$ atom in titanium alloy is a constant at specific temperature. Therefore, the Eq. (2) can be applied to deduce diffusion coefficients of $\mathrm{Fe}$ atom in titanium alloy.

Aiming to shortening length of the paper, it is well note that just simulated profiles at $850^{\circ} \mathrm{C}$ and $900^{\circ} \mathrm{C}$ are listed in 
Table 6. Diffusion coefficient and diffusion activation of Fe atom at different temperature.

\begin{tabular}{|c|c|c|c|c|c|}
\hline Bonding temperature $\left(\mathrm{T} /{ }^{\circ} \mathrm{C}\right)$ & 800 & 825 & 850 & 875 & 900 \\
\hline $\begin{array}{l}\text { Diffusion coefficient in nanostructured } \\
\text { sample }\left(D / \mathrm{m}^{2} \mathrm{~s}^{-1} \times 10^{-13}\right)\end{array}$ & 1.059 & 1.378 & 1.555 & 2.143 & 2.502 \\
\hline $\begin{array}{l}\text { Diffusion coefficient in coarse grain } \\
\text { sample }{ }^{[18]}\left(D / \mathrm{m}^{2} \mathrm{~s}^{-1} \times 10^{-13}\right)\end{array}$ & 0.540 & 0.83 & 1.095 & 1.428 & ---- \\
\hline $\begin{array}{c}\text { Diffusion activation energy in } \\
\text { nanostructured sample }\left(Q / \mathrm{kJ} \cdot \mathrm{mol}^{-1}\right)\end{array}$ & & & 71.61 & & \\
\hline $\begin{array}{l}\text { Diffusion activation energy in coarse } \\
\text { grain sample }{ }^{[18]}\left(\mathrm{kJ} \cdot \mathrm{mol}^{-1}\right)\end{array}$ & & & 202.75 & & \\
\hline
\end{tabular}

the paper (as shown in Fig. 6)

According to the above simulated curves, the Fe atom concentrations range between $13-15$ at $\%$ while $x$ being equation to 0 , which indicates the initial concentrations of Fe atom are no more than $30 \mathrm{at} \%$ and meeting the above supposed condition, therefore, the $C_{0}$ may be determined as $30 \mathrm{at} \%$.

While $D$ being a constant, the Eq. (2) has following error function (3):

$$
C(x, t)=\frac{C_{0}}{2}\left[1-\operatorname{erf}\left(\frac{x}{2 \sqrt{D t}}\right)\right] .
$$

Thereby, the Eq. (2) may be transformed into Eq. (4) as following:

$$
\operatorname{erf}\left(\frac{x}{2 \sqrt{D t}}\right)=1-\frac{2 C}{C_{0}}
$$

Supposing, $Z=x / 2 \sqrt{D t}, Z$ can be determined according to error function table. Consequently, the diffusion coefficient $D$ can be obtained following Eq. (5):

$$
D=\frac{x^{2}}{4 Z^{2} t}
$$

At last, diffusion coefficients of Fe atom in titanium were obtained at different temperatures, as shown in Table 6. The results shows the diffusion coefficients of $\mathrm{Fe}$ atom in Ti-4Al-2V alloy with nanostructured surface layer are larger than that in coarse grain counterpart, and the diffusion coefficients of $\mathrm{Fe}$ are increased with increasing of bonding temperature.

According to Arrhenius diffusion equation, ${ }^{20)}$ a equation can be deduced here as following Eq. (6):

$$
D=D_{0} \exp \left(-\frac{Q}{R T}\right)
$$

Where $D_{0}$ is diffusion coefficient constant, $Q$ is mole activation energy, $R$ and $T$ are gas constant and Kelvin temperature respectively. In term of specific material, $D_{0}$ and $Q$ are constants which are independent of temperature and can be determined by experiment.

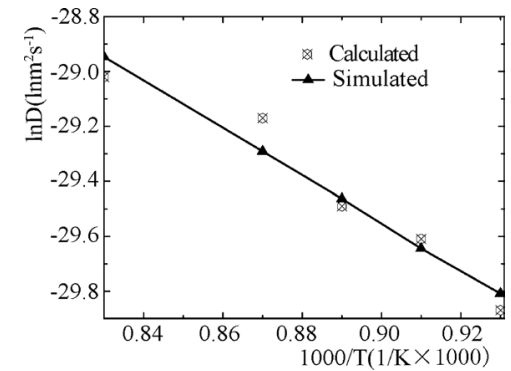

Fig. 7. Plot of $\ln D$ versus $1 / T$ in the temperature rang of $800-900^{\circ} \mathrm{C}$.

The Eq. (6) can be transformed into Eq. (7):

$$
\ln D=\ln D_{0}-\frac{Q}{R T}
$$

Obviously, $\ln D$ becomes linear function of $1 / T$. Therefore, $D_{0}$ and $Q$ can be determined by simulating profile of $\ln D$ versus $1 / T$, and Eq. (6) can be determined also. Thus, the diffusion coefficient of $\mathrm{Fe}$ atom in the Ti-4Al-2V can be obtained in different bonding temperature. The straightline of $\ln D$ versus $1 / T$ can be plotted according to diffusion coefficients in the Table 6, as shown in Fig. 7, and a simulated Eq. (8) can be obtained:

$$
\ln D=-8.622 \times 1000 / T-21.79 \text {. }
$$

According to Eqs. (7) and (8), the $D_{0} Q$ and can be determined as following:

$$
\begin{gathered}
D_{0}=3.4413 \times 10^{-10} \mathrm{~m}^{2} \cdot \mathrm{s}^{-1} \\
Q=71.61 \mathrm{~kJ} \cdot \mathrm{mol}^{-1}
\end{gathered}
$$

Substituting the values of $D_{0}$ and $Q$ into Eq. (6), the equation can be transformed into Eq. (9):

$$
D=3.4413 \times 10^{-10} \exp \left(-\frac{71605.73}{R T}\right)
$$

\section{Discussion}

Prior period research of the present work shows, in the course of surface self-nanocrystallization by means of 
HESP, coarse grains in $\mathrm{Ti}-4 \mathrm{Al}-2 \mathrm{~V}$ alloy are transformed into low density single-system twin lamella under low stress and strain rate, with increasing of stress and strain rate, the twin density is incremented and multi-system twin is generated. While the strain rate is increased to a certain level, dislocation slip is excitated in fine twin lamella and formed high density dislocation walls (DDWs) on the twin boundaries, and then fine twin lamella is divided into low angle subgrains, with further increasing of stress and strain rate, sub-boundaries are rotated due to dislocation slip, at last, large angle equiaxial nanograins with an average size of $35 \pm 5 \mathrm{~nm}$ are formed on the top surface, and some $50 \mu \mathrm{m}$ thick surface nanostructured layer with nanograins no more than $100 \mathrm{~nm}$ are formed. ${ }^{21,22)}$ However, as for 0Cr18Ni9Ti stainless steel, under low stress, dislocations slip along themselves gliding planes and accumulate because of intercrossing each other, with increasing of stress and strain rate, twin deformation are induced on the dislocation accumulating place, and then multi-system twin deformation refined coarse grains within $80 \mu \mathrm{m}$ to top surface into nanograins with below $100 \mathrm{~nm}$, at the same time, induced martensite phase transformation are yielded on the twins intersections ${ }^{23,24)}$

Therefore, surface nanostructured layers on the ends of Ti-4Al-2V and 0Cr18Ni9Ti were formed after surface selfnanocrystallization by means of HESP, and a great many of non-equilibrium grain boundaries and subboundaries were introduced into the nanostructured layer. Research ${ }^{10)}$ shows the ultrafinegrained structure provides about $30 \mathrm{vol} \%$ grain boundaries for average grain size of $10 \mathrm{~nm}$, and a few volume percents triple junctions. In present work, at certain diffusion bonding temperature, these numerous non-equilibrium grain boundaries and subboundaries in the nanostructured layer act as fast atomic diffusion channels. Meanwhile, these numerous non-equilibrium phase possess higher Gibbs free energy which may facilitate the chemical reaction than that conventional grain boundaries, which decreased the atomic diffusion activation energy ${ }^{10}$ (as shown in Table 6). Therefore, in the course of diffusion bonding of $\mathrm{Ti}-4 \mathrm{Al}-2 \mathrm{~V}$ and $0 \mathrm{Cr} 18 \mathrm{Ni}$ Ti, atomic diffusion in the diffusion layer with nano-microstructures is boosted. Comparing with coarse grain samples, the diffusion coefficient and the diffusion distance of atom in the HESP treated samples are larger, as shown in the mentioned above 3.3 and Table 6 .

Figure 8 shows the longitudinal section SEM images of bond joints at different bonding temperature, regions $\mathrm{A}, \mathrm{B}$, C, D and E correspond with ones respectively in the Fig. 5. Obviously, the breadth of region B (acicular $\alpha-\beta$ Ti), $\mathrm{C}(\beta-$ Ti solid solution) and D (intermetallic compound) become increasing with rising of bonding temperature.

CTPDB was applied to bonding of CP-Ti and AISI304 stainless steel at $850^{\circ} \mathrm{C}, 3 \mathrm{MPa}$ and $120 \mathrm{~min}$ by M.Ghosh et $a l$, and the maximum bond strength of $222 \mathrm{MPa}$ was obtained, M. Ghosh ${ }^{25,26)}$ held reduction of bond strength resulted chiefly from increasing of brittle intermetallic compound and segregation layer, as well as growth of grains in the diffusion layer. Literature ${ }^{27)}$ insisted bonding property of titanium alloy and stainless steel is chiefly dependence of the thickness of brittle intermetallic compound and combination strength of base materials, early stage of diffusion bonding, the intermetallic compound influences slightly the

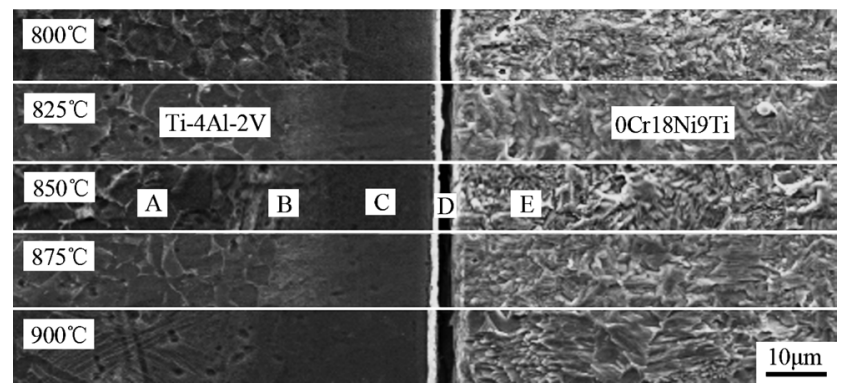

Fig. 8. Longitudinal section SEM of joints at different temperature.

bond strength due to no formation of continuing compound layer on the bond interface, $3-5 \mu \mathrm{m}$ thick continuous brittle intermetallic compound was generated when bonding temperature is exorbitant or bonding time is more long, which decreased heavily the bond strength. In present work, while bonding temperature being less than $850^{\circ} \mathrm{C}$, atoms have not diffused completely in diffusion layer after $20 \mathrm{~min}$ diffusion bonding, and intermetallic compound is not chief factors of influencing bond strength. However, intermetallic compound layer was increased obviously when the bonding temperature was more than $850^{\circ} \mathrm{C}$, which decreased the bond strength primarily after 20 min diffusion bonding (as shown in Table 3), the thickness of intermetallic compound is about $2 \mu \mathrm{m}$ at $850^{\circ} \mathrm{C}$, and it is about $3.5 \mu \mathrm{m}$ at $900^{\circ} \mathrm{C}$ (as shown in Fig. 8), the experiment result is good consistent with research result in the literature. ${ }^{27)}$

Due to fine nanograins and plenty of grain boundaries in the diffusion layer after surface selfnanocrystallization, in the course of diffusion bonding, $\mathrm{Fe}, \mathrm{Cr}$, Ni and $\mathrm{Ti}$ atoms can diffuse into matrix as soon as possible before nanograins do not grow completely, which result in reducing the thickness of intermetallic compound. Furthermore, after diffusion bonding, grains (about several micron in size, as shown in Fig. 8) closing diffusion interface are homogeneous and far less than convention coarse grain dimension. These factors facilitate to improve the property of joints. However, as for counterpart coarse grain samples, a plenty of atoms can not diffuse quickly into matrix, which results in accumulating a majority of atoms at the interface and increases the thickness of intermetallic compound. Consequently, at same diffusion bonding process, the bond strength of SSNC sample is higher than that of convention sample.

\section{Conclusion}

(1) On the ends of Ti-4Al-2V titanium alloy and $0 \mathrm{Cr} 18 \mathrm{Ni}$ Ti austenite stainless steel bars, some $50 \mu \mathrm{m}$ and $80 \mu \mathrm{m}$ thickness surface nanostructured layer consisting of nanograins with below $100 \mathrm{~nm}$ were obtained respectively by means of HESP.

(2) Using the treated surface for mating surface, CTPDB was applied to prepare joints of Ti-4Al-2V titanium alloy and $0 \mathrm{Cr} 18 \mathrm{Ni}$ Ti austenite stainless steel, and tightening joints were obtained in the temperature rang of $800-900^{\circ} \mathrm{C}$ for $20 \mathrm{~min}$ under a uniaxial load of $8 \mathrm{MPa}$ in vacuum. When bonding temperature was at $850^{\circ} \mathrm{C}$, the maximum tensile strength of $327 \mathrm{MPa}$ was obtained. 
(3) In the course of diffusion bonding of treated Ti-4Al-2V alloy and 0Cr18Ni9Ti stainless steel bars, the diffusion activation energy of $\mathrm{Fe}$ atom in titanium alloy is far less than that in coarse grains sample, the diffusion coefficient of Fe atom is higher than that in coarse grain sample, the bond strength of joints are increased greatly. Therefore, the surface self-nanocrystallization for mating surface by means of HESP redounds to improving tensile property of joints between $\mathrm{Ti}-4 \mathrm{Al}-2 \mathrm{~V}$ alloy and $0 \mathrm{Cr} 18 \mathrm{Ni9Ti}$ stainless steel rods.

\section{Acknowledgements}

The author acknowledges financial support from the National Science Foundation of China (No. 50675234). The author acknowledges financial support from the Great Equipments Opening Foundation of Chongqing University. The author acknowledges financial support from Chongqing University Postgraduates' Science and Innovation Fund (No.200801A1B0100269).

\section{REFERENCES}

1) X. Y. Zhang, Y. Q. Zhao and C. G. Bai: Titanium Alloy and Application [M], Chemical Industry Press, Beijing, (2005), 15.

2) M. M. Wang, Y. Q. Zhao and L. Zhou: Rare Met. Mater. Eng., 31 (2002), No. 2, 135

3) H. Gleiter: Prog. Mater. Sci., 33 (1989), No. 4, 223.

4) K. Lu: Mater. Sci. Eng. R: Reports, 16 (1996), No. 4, 161.

5) K. Lu and J. Lu: Chinese Patent, No. 01122980.2[P], 2, (2001); French Patent, FR2812284[P], (2001).

6) S. Schumacher, R. Birringer, R. Strauss and H. Gleiter: Acta Metall., 37 (1989), No. 9, 2485.

7) L. Lu, M. L. Sui and K. Lu: Science, 287 (2000), No. 2, 1463.
8) W. P. Tong, N. R. Tao, Z. B. Wang, J. Lu and K. Lu: Science, 299 (2003), No. 1, 686

9) Z. B. Wang, N. R. Tao, W. P. Tong, J. Lu and K. Lu: Acta Mater, 51 (2003), No. 14, 4319.

10) Z. B. Wang, J. Lu and K. Lu: Acta Mater, 53 (2005), No. 7, 2081.

11) W. P. Tong, N. R. Tao, Z. B. Wang, J. Lu and K. Lu: J. Grad. Sch. Chin. Acad. Sci., 22 (2005), No. 2, 230.

12) H. W. Zhang, L. Wang, Z. K. Hei, G. Liu, J. Lu and K. Lu: Z. Metallkd., 94 (2003), No. 5, 1143.

13) D. H. Bei, J. F. Gu, J. H. Pan, J. Lu and K. Lu: J. Mater. Sci. Technol., 18 (2002), No. 6, 566.

14) S. Kundu and S. Chattterjee: Mater. Sci. Eng. A, A480 (2008), No. $1-2,316$.

15) Y. C. Zhang and H. Chen: Rear Met., 18 (1994), No. 6, 464.

16) B. Qin, G. M. Sheng, B. Zhou, J. W. Huang and C. Li: Chin. J. Nonferrous Met., 14 (2004), No. 9, 1546.

17) B. Qin, G. M. Sheng, J. W. Huang and C. Li: Trans. Chin. Weld. Inst., 27, (2006), No. 1, 41.

18) B. Qin: Technique and Theory Research on Diffusion Bonding of Titanium Alloy to Stainless Steel[D], Chongqing University, Chongqing, (2006).

19) H. Z. Qiu and Z. H. Wu: Aerosp. Mater. Technol., (1997), No. 4, 5.

20) Н. Ф. Казков compile, K. S. He version: Diffusion Bonding of Materials[M], National Defence Industry Press, Beijing, (1982), 26.

21) K. Y. Zhu, A. Vassel, F. Brisset, K. Lu and J. Lu: Acta Mater, 52 (2004), No. 14, 4101.

22) J. Han, G. M. Sheng and G. X. Hu: ISIJ Int., 48 (2008), No. 2, 218.

23) N. R. Tao, H. W. Zhang, J. Lu and K. Lu: Mater. Trans., 44 (2003), No. $10,1919$.

24) G. X. Hu: Investigation of Processing, Characterization and Mechanism of Surface Self-nanocrystallization in Metallic Material[D], Chongqing University, Chonqing, (2007).

25) M. Ghosh and S. Chatterjee: Mater. Charact., 48 (2002), No. 5, 393.

26) M. Ghosh, K. Bhanumurthy, G. B. Kale, J. Krishnan and S. Chatterjee: J. Nucl. Mater., 322 (2003), No. 2, 3, 235.

27) P. He, J. C. Feng and Y. Y. Qian: Mater. Sci. Technol., 11 (2003), No. 2,144 . 